\title{
Identification of virion-associated transcriptional transactivator (VATT) of SGIV ICP46 promoter and their binding site on promoter
}

Li-Qun Xia ${ }^{1,2,3,4}$, Jian-Lin Chen ${ }^{1,2,3,4}$, Hong-Lian Zhang ${ }^{1,2,3,4}$, Jia Cai ${ }^{1,2,3,4}$, Sheng Zhou ${ }^{4,5}$ and Yi-Shan Lu ${ }^{1,2,3,4^{*}}$

\begin{abstract}
Background: Iridoviruses are large DNA viruses that cause diseases in fish, amphibians and insects. Singapore grouper iridovirus (SGIV) is isolated from cultured grouper and characterized as a ranavirus. ICP46 is defined to be a core gene of the family Iridoviridae and SGIV ICP46 was demonstrated to be an immediate-early (IE) gene associated with cell growth control and could contribute to virus replication in previous research.

Methods: The transcription start site (TSS) and 5'-untranslated region (5'-UTR) of SGIV ICP46 were determined using 5' RACE. The core promoter elements of ICP46s were analyzed by bioinformatics analysis. The core promoter region and the regulation model of SGIV ICP46 promoter were revealed by the construction of serially deleted promoter plasmids, transfections, drug treat and luciferase reporter assays. The identification of virion-associated transcriptional transactivator (VATT) that interact with SGIV ICP46 promoter and their binding site on promoter were performed by electrophoretic mobility shift assays (EMSA), DNA pull-down assays and mass spectrometry (MS).

Results: SGIV ICP46 was found to have short 5'-UTR and a presumptive downstream promoter element (DPE), AGACA, which locates at +36 to $+39 \mathrm{nt}$ downstream of the TSS. The core promoter region of SGIV ICP46 located from -22 to + $42 \mathrm{nt}$ relative to the TSS. VATTs were involved in the promoter activation of SGIV ICP46 and further identified to be VP12, VP39, VP57 and MCP. A 10-base DNA sequence "ATGGCTITCG" between the TSS and presumptive DPE was determined to be the binding site of the VATTs.

Conclusion: Our study showed that four VAATs (VP12, VP39, VP57 and MCP) might bind with the SGIV ICP46 promoter and be involved in the promoter activation. Further, the binding site of the VATTs on promoter was a 10-base DNA sequence between the TSS and presumptive DPE.
\end{abstract}

Keywords: Singapore grouper iridovirus (SGIV), ICP46, Promoter, Virion-associated transcriptional transactivator (VATT), Downstream promoter element (DPE)

\section{Background}

Iridoviruses are large DNA viruses that cause diseases in fish, amphibians, reptiles and insects, and result in significant economic and ecological losses [1,2]. Similar to other large dsDNA viruses, the gene transcription of iridoviruses can be divided into 3 categories according to

\footnotetext{
*Correspondence: fishdis@163.com

'Shenzhen Institute of Guangdong Ocean University, Shenzhen City, Guangdong, China

${ }^{2}$ College of Fisheries, Guangdong Ocean University, Zhanjiang City,

Guangdong, China

Full list of author information is available at the end of the article
}

the sequence: immediate-early (IE), early (E) and late (L), their corresponding protein encoding are very early protein, early protein and late protein [3-5]. As the first step of viral temporal expression, IE genes are the earliest genes expressed in the cells after virus infection, and the transcription of IE genes are essential for the ordered cascade of viral life events, such as manipulating the transcription of $\mathrm{E}$ genes and $\mathrm{L}$ genes, affecting the expression of host genes, controlling cell cycle and regulating apoptosis $[6,7]$. Therefore, the transcription of IE genes is a key point in the viral infection cycle. In

(C) The Author(s). 2019 Open Access This article is distributed under the terms of the Creative Commons Attribution 4.0 International License (http://creativecommons.org/licenses/by/4.0/), which permits unrestricted use, distribution, and 
recent years, the study on the promoter and transcriptional regulation of virus IE genes has become a research focus [8-10].

ICP46 was firstly found to encode a very early protein of approximately $46 \mathrm{kDa}$ in frog virus 3 (FV3), and have been identified as IE genes in FV3, SGIV and Bohle iridovirus (BIV) [11-13]. By comparative genomic analysis, ICP46 is defined to be one of the Iridoviridae core genes and might play an essential role in the life cycle of iridoviruses [14]. It has been concluded that the transcription of FV3 ICP46 might be activated by certain virion-associated transcriptional transactivator (VATT) and depressed by at least one of the early proteins $[6,12]$. Whereas the molecular identities of VATT and their precise mechanism of function are unknown. Our previous study demonstrated that SGIV ICP46 is an IE gene associated with cell growth control and contributes to virus replication, the transcription of SGIV ICP46 starts at $2 \mathrm{~h}$ p.i. and shows a high transcription level throughout the SGIV infection cycle [11]. It also revealed that SGIV ICP46 is a structural protein in virus nucleocapsid and aggregates mainly in cytoplasm of host cells during infection [11]. So far, the promoter sequence and transcriptional regulation of SGIV ICP46 are still unclear.

In the present study, we revealed the core region of SGIV ICP46 promoter, investigated the regulation model of SGIV ICP46 promoter associated with viral protein, identified the VATTs that interact with the SGIV ICP46 promoter, and determined the binding site of VATTs on SGIV ICP46 promoter. This study is important for the further study of the transcriptional regulation mechanism of SGIV ICP46, and contributes to better understanding of the iridovirus transcription, ultimately helps to develop novel control strategies for iridovirus diseases.

\section{Methods}

Virus and cell cultures

Grouper spleen (GS) cells were cultured at $25^{\circ} \mathrm{C}$ in Leibovitz's L-15 medium containing 10\% fetal bovine serum (Gibco-BRL, Grand Island, NY, USA). Singapore grouper iridovirus (SGIV, strain A3/12/98 PPD) was propagated on GS cell monolayers as previously described [15]. Preparation of the SGIV suspension and purified SGIV virion were performed as described by Qin [16], and SGIV stored at $-80^{\circ} \mathrm{C}$ until use. For SGIV infection, cells were infected with SGIV at a multiplicity of infection (MOI) of 2 in the following experiments.

According to Huang's method, UV-inactivated virus was treated by exposing SGIV suspension under a $30-\mathrm{W}$ UV light source $\left(10 \mathrm{~cm}\right.$ distant) for $30 \mathrm{~min}$ at $4{ }^{\circ} \mathrm{C}$ [17]. Heat-inactivated virus was obtained by $55^{\circ} \mathrm{C}$ water bath for $30 \mathrm{~min}$. Inactivated SGIV were stored at $-80^{\circ} \mathrm{C}$ until use.

\section{5'-untranslated region (5'-UTR) analysis}

Transcription start site (TSS) of SGIV ICP46 mRNA was determined using 5' RACE System for Rapid Amplification of cDNA Ends (Invitrogen, Carlsbad, CA, USA) according to the manufacturer's instructions. First strand cDNA was synthesized from $3 \mu \mathrm{g}$ total RNA isolated at $12 \mathrm{~h}$ p.i. using a specific reverse primer (GSP1, $5^{\prime}$-CAA AGG GTG TGG CAA G-3'). After RNAase treatment and $\mathrm{CDNA}$ purification, an oligo $(\mathrm{dC})$ tail was added at the $5^{\prime}$ end. The resulting product was PCR amplified with a universal primer containing a poly-dG sequence and specific oligonucleotides (GSP2, 5' -TTT CCG CAG TGT ACG AGT CC-3'; GSP3, 5'-GAC GCG CAA GAC ATT GTG AG-3') for the first and second PCR respectively. The amplified fragment was cloned into plasmid pMD18-T (TaKaRa, Dalian, China) and analyzed by automated sequencing (Sangon, Shanghai, China).

\section{Bioinformatics analysis}

The TSS and 5'-UTR of SGIV ICP46 were performed bioinformatics analysis. According to the DNA sequences flanking the TSS $(-300$ to +200$)$, the core promoter elements were analyzed for the TATA-box (TATA), CAAT-box ((C)CAAT) and downstream promoter element (DPE) (RGWYV (T)). Moreover, about 200 nucleotides (nt) flanking sequence of translation initiation site (TIS) from SGIV ICP46 and other 13 iridovirus ICP46s were chosen from the genome data of the NCBI blast server (Table 1), multiple nucleic acids sequence alignment was performed using Clustal X 1.83 and edited by the GeneDoc program. The potential TATA-box, CAAT-box and DPE were noted through bioinformatics analysis or previous reports $[12,13]$ on fourteen iridovirus ICP46s.

\section{Plasmids construction of SGIV ICP46 promoter}

Viral DNA was extracted from SGIV infected cells according to Xia's method [18]. A luciferase reporter gene system was used to assay different lengths of SGIV ICP46 flanking region for promoter activity. According to the SGIV genome databases [19], with reference sequence ID (YP 164257.1), primers were designed to contain restriction sites for directional cloning as shown in Table 2. Recombinant plasmids were constructed by generating deletion mutants starting at positions - 3247, - 2180, - 1535, 1159 or -649 nt for SGIV ICP46 relative to the TSS. These promoter fragments were amplified by PCR from SGIV DNA using KOD-plus-Neo DNA polymerase (Toyobo, Osaka, Japan). The primers introduced KpnI restriction site at the $5^{\prime}$ end of the sequences. The primer at the 3' end (Luc R1) annealed from position $+44 \mathrm{nt}$ for SGIV ICP46 relative to the TSS and introduced a BglII restriction site. The amplified DNA fragment was digested with KpnI and BglII and cloned in-frame with a luciferase 
Table 1 The core promoter elements analysis of iridovirus ICP46s

\begin{tabular}{|c|c|c|c|c|c|c|c|}
\hline Genus & Virus (Abbreviation) & Accession no. ${ }^{a}$ & $\begin{array}{l}\text { TAT } \\
\text { A-box }\end{array}$ & $\begin{array}{l}\text { CAAT } \\
\text {-box }\end{array}$ & DPE & $\begin{array}{l}\text { DPE } \\
\text { sequence }\end{array}$ & $\begin{array}{l}\text { DPE } \\
\text { location }^{b}\end{array}$ \\
\hline \multirow[t]{6}{*}{ Ranavirus } & Singapore grouper iridovirus (SGIV) & AY521625.1: 139773-139972 & - & - & + & AGACA & $+13 \mathrm{nt}$ \\
\hline & Grouper iridovirus (GIV) & AY666015.1: 128748-128948 & - & - & + & AGACA & $+13 \mathrm{nt}$ \\
\hline & Frog virus 3 (FV3) & AY548484.1: $98710-98909$ & + & + & - & - & - \\
\hline & Soft-shelled turtle iridovirus (STIV) & EU627010.1: 98502-98701 & + & + & - & - & - \\
\hline & Ambystoma tigrinum virus (ATV) & AY150217.1: 16087-16286 & + & + & - & - & - \\
\hline & Tiger frog virus (TFV) & AF389451.1: 97303-97502 & + & + & - & - & - \\
\hline \multirow[t]{3}{*}{ Lymphocystivirus } & Lymphocystis disease virus 1 (LCDV-1) & NC_001824.1: 23614-23813 & + & - & - & - & - \\
\hline & Lymphocystis disease virus China (LCDV-C) & AY380826.1: 120663-120852 & + & - & + & AGTTCT & $+23 \mathrm{nt}$ \\
\hline & Lymphocystis disease virus SA (LCDV-SA) & KX643370.1: 143502-143691 & + & - & + & AGTTC & $+23 \mathrm{nt}$ \\
\hline Iridovirus & Chilo iridescent virus (CIV) & AF303741.1: 175726-175925 & + & - & - & - & - \\
\hline Chloriridovirus & Invertebrate iridescent virus 3 (IIV-3) & DQ643392.1:59302-59701 & + & - & - & - & - \\
\hline \multirow[t]{3}{*}{ Megalocytivirus } & Infectious spleen and kidney necrosis virus (ISKNV) & AF371960.1: 103053-103252 & + & + & + & AGACA & $+9 \mathrm{nt}$ \\
\hline & Orange-spotted grouper iridovirus (OSGIV) & AY894343.1: $104326-104525$ & + & + & + & AGACA & $+9 \mathrm{nt}$ \\
\hline & Rock bream iridovirus (RBIV) & KC244182.1: 103958-104157 & + & + & + & AGACA & $+9 \mathrm{nt}$ \\
\hline
\end{tabular}

a GenBank accession numbers of about 200 nucleotides sequences flanking the translation initiation site (TIS) of iridovirus ICP46s ( from about 150 nt upstream to about $50 \mathrm{nt}$ downstream of TIS).

b DPE location relative to "A" of TIS.

nt Nucleotides.

a GenBank accession numbers of about 200 nucleotides sequences flanking the translation initiation site (TIS) of iridovirus ICP46s (from about 150 nt upstream to about $50 \mathrm{nt}$ downstream of TIS)

b DPE location relative to " $A$ " of TIS

nt Nucleotides

reporter gene in the vector pGL4.17 (Promega, Madison, WI, USA). In this way the promoter plasmids P-3247, P2180, P-1535, P-1159 and P-649 were generated. Other 9 serially deleted promoter plasmids for SGIV ICP46 (- 559, $-502,-442,-360,-279,-196,-136,-82$ and - 22) were amplified by PCR from the P-649 promoter plasmid. The primers directed against the $5^{\prime}$ end had KpnI restriction sites as described above. At the $3^{\prime}$ end, a primer (Luc R2) was used that annealed from position $+42 \mathrm{nt}$ for SGIV ICP46 relative to the TSS. The resulting DNA fragments were cloned between the KpnI and BglII sites of pGL4.17, thereby generating
P-559, P-502, P-442, P-360, P-279, P-196, P-136, P-82 and P-22 promoter containing plasmids. When the major determinant region for promoter activity was confirmed, a key-region-deleted reporter plasmid (P$\Delta 196)$ was constructed using primer Luc F-196 and Luc R3 (Table 2).

These different plasmids were sequenced for verification of the correct insert (Sangon, Shanghai, China). Plasmids were purified using a Plasmid Endo-free Mini Kit (Invitrogen, Carlsbad, CA, USA) and the DNA concentrations were determined by spectrophotometry (Nanodrop, Wilmington, DE,USA).

Table 2 Oligonucleotides used for the preparation of the various promoter plasmids

\begin{tabular}{|c|c|c|}
\hline Primer name & Sequences $\left(5^{\prime}-3^{\prime}\right)$ & Position \\
\hline Luc F-3247 & 5'-GGTACCCATCGCGATTCCCTTCATGAGAC-3' & $-3247 /-3225$ \\
\hline Luc F-2180 & 5'-GGTACCCCCAAGTGGCGGCGTTGTATGTG-3' & $-2180 /-2158$ \\
\hline Luc F-1535 & 5'-GGTACCGGCCGGAAGAGTTTCCGTCCTGC-3' & $-1535 /-1513$ \\
\hline Luc F-1159 & 5'-GGTACCCTTTCCTCGCGAACGCGACAAG-3' & $-1159 /-1137$ \\
\hline Luc F-649 & 5'-CGGGGTACCCATTCCCATGCTGTCCGCCAAG-3' & $-649 /-628$ \\
\hline Luc R1 & 5'-CCTAGATCTCGCTTGTCTGTGACGAAAGCCAT-3' & $+22 /+44$ \\
\hline Luc F-559 & 5'-GGGTACCCCCAGAGTACAAACACGATC-3' & $-559 /-540$ \\
\hline Luc F-502 & 5'- GGGGTACCGCTCTCGGCAATCAAAATCA-3' & $-502 /-483$ \\
\hline Luc $\mathrm{F}-442$ & 5'-GGGGTACCAACAGAGACGCAAAAAGACT-3' & $-442 /-423$ \\
\hline Luc F-360 & 5'-GGGGTACCCCAAATTACGCCTTACCAGA-3' & $-360 /-341$ \\
\hline Luc F-279 & 5'-GGGGTACCAAACTCACAGACCAATGCA-3' & $-279 /-251$ \\
\hline Luc F-196 & 5'-GG GGTACCCAGCGAGTACGAAATGATAAAG-3' & $-196 /-175$ \\
\hline Luc F-136 & 5'-GGGGTACCCTATCACCAATTGGCAGTGTC-3' & $-136 /-116$ \\
\hline Luc F-82 & 5'-GGGGTACCCGATATTTTAACCTTTTAAAAGGTTAAAATATC-3' & $-82 /-50$ \\
\hline Luc $\mathrm{F}-22$ & 5'-GGGGTACCGCGCAAACTCGGAACAAAAATC-3' & $-22 /-1$ \\
\hline Luc R2 & 5'-GAAGATCTCTTGTCTGTGACGAAAGCCA-3' & $+23 /+42$ \\
\hline Luc R3 & 5'-CCTAGATCTAAACTCGCTAATCAAGTTTTTTTAC-3' & $-47 /-23$ \\
\hline
\end{tabular}

Restriction sites were added to the gene specific SGIV ICP46 primers to assist cloning into the reporter vector pGL4.17; The underline shows the restriction enzyme Kpnl and Bglll 


\section{Transfections and luciferase reporter assays}

GS cells were seeded in 24 well plates at a density of $2.5 \times 10^{5}$ cells per well in $500 \mu \mathrm{l}$ of media and allowed to adhere overnight. All transient co-transfection experiments for luciferase reporter assays were carried out using $500 \mathrm{ng}$ of each of the promoter reporter plasmids together with $50 \mathrm{ng}$ of thymidine kinase promoterRenilla luciferase reporter plasmid (pRL-TK) and Lipofectamine 2000 according to the manufacturer's instructions (Invitrogen, Carlsbad, CA, USA). At $24 \mathrm{~h}$ after transfection, cells were infected with SGIV at MOI of 2 and further incubated at $25^{\circ} \mathrm{C}$. Cells were harvested at 6 h p.i. for promoter analysis. Firefly and Renilla luciferase activities were measured in cell extracts using the dual luciferase reporter assay system (Promega, Madison, WI, USA) following the manufacturer's instructions.

\section{Promoter activity assay}

To clarify the regulation pattern of viral proteins on the activity of SGIV ICP46 promoter, GS cells were transfected with P-22, which containing the critical promoter regions, and then the transfected cells were either mock infected or infected with infectious SGIV, heat-inactivated SGIV and UV-inactivated SGIV, respectively. The GS cells transfected with pGL 4.17 were served as negative control. Finally, the luciferase reporter assays were carried out.

To analysis whether the newly synthesized viral proteins can influence the activity of SGIV ICP46 promoter, GS cells were transfected with P-22 and then the transfected cells were pretreated with $50 \mu \mathrm{g} / \mathrm{ml}$ cycloheximide (CHX) or $100 \mu \mathrm{g} / \mathrm{ml}$ cytosine arabinofuranoside (AraC) for $1 \mathrm{~h}$ before and throughout the SGIV infection. CHX or AraC-pretreated cells were infected with SGIV at MOI of approximately 2, then harvested at 6 and $48 \mathrm{~h}$ p.i., respectively. The P-22 transfected GS cells infected with SGIV were collected at the same time points and served as negative control. The luciferase reporter assays were carried out following the manufacturer's instructions.

\section{Electrophoretic mobility shift assay}

To confirm that the SGIV proteins may bind with the core region of SGIV ICP46 promoter, the electrophoretic mobility shift assay (EMSA) were carried out. According to the core promoter of SGIV ICP46, the $64 \mathrm{nt}$ EMSA probe named as probe $\mathrm{X}$ was design and synthesis, the sequence of probe $\mathrm{X}$ is $5^{\prime}$-GCGCA AACTC GGAAC AAAAA TCGCC CTTGT GGAAG ATTTA AAAAT GGCTT TCGTC ACAGA CAAG - 3'. The whole protein extraction from GS cells (GS), SGIV-infected GS cells (SGIV+GS), CHX-pretreated and SGIVinfected GS cells $(\mathrm{CHX}+\mathrm{SGIV})$, AraC-pretreated and SGIV-infected GS cells (AraC+SGIV) and purified SGIV virion (SGIV) were obtained using the Cytoplasmic
Protein/Nuclear Protein Extraction Kit (Viagene Biotech, Changzhou, China) according to the manufacturer's instructions. Then the EMSA were performed using NonRadioactive EMSA Kits (Viagene Biotech, Changzhou, China) following the manufacturer's protocol. Briefly, the whole protein extraction $(5 \mu \mathrm{g})$ from GS, SGIV+GS, CHX + SGIV, AraC+SGIV cells and purified SGIV virion were incubated with biotin-labeled probe $\mathrm{X}$ in reaction buffers for $20 \mathrm{~min}$ at room temperature. Incubated with biotin-labeled probe $N_{F} \mathrm{~B}$, the nuclear extracts with activated NFKB was used as positive control and nuclear extracts without activated $\mathrm{NF \kappa B}$ was used as negative control. Protein-DNA complex was separated from free oligonucleotide on $5.5 \%$ nondenaturant polyacrylamide gels, and then transferred to positively charged nitrocellulose membranes (Milipore, Bedford, MA) by wet trans-blot. After the transfer, the crosslink DNA on the membrane was immobilized in a UV linker (Stratagene Stratalinker 1800). Then the binding-membrane was visualized with streptavidin-horseradish peroxidase followed by chemiluminescent detection.

\section{DNA pull-down assays}

DNA pull-down experiments were performed using Pulldown Kits for Using Biotin-Probes (Viagene Biotech, Changzhou, China) according to the manufacturer's instructions. Briefly, the whole protein extraction (30$90 \mu \mathrm{g}$ ) from GS, SGIV+GS, CHX + SGIV, AraC+SGIV cells and purified SGIV virion were incubated with the biotin-labeled probe $\mathrm{X}(6-10 \mathrm{nmol})$ and non-specific competitors for $60 \mathrm{~min}$ at room temperature. Then the DNA/Protein binding mixture were bound to streptavidin-agarose beads by incubating $40 \mathrm{~min}$ at room temperature with gently shake, and washed three times to remove unbound DNA/Protein. Beads-bound proteins were dissociated by boiled for $5 \mathrm{~min}$ in a dissociation solution and separated by electrophoresis on a SDS-10\% polyacrylamide gel. The differential protein bands were chosen and identified by NanoLC-ESI-MS/MS Analysis (ProtTech, Suzhou, China).

\section{Analysis of transient expression of VATTs on SGIV ICP46 promoter activity}

The full length genes (SGIV ORF012, ORF039, ORF057 and ORF072) encoding four VATTs of SGIV ICP46 promoter identified by DNA pull-down assays were cloned into eukaryotic vectors pcDNA3.1/His A (Invitrogen, Carlsbad, CA, USA) using corresponding primers (Table 3). These different constructs were confirmed by restriction enzyme digestion and DNA sequencing, then named as pcDNA-012, pcDNA-039, pcDNA-057 and pcDNA-072. At $24 \mathrm{~h}$ post transfection of GS cells with above recombinant vectors, RT-PCR was used to verify their expression in GS cells. To value the effect of these 
VATTs on the activity of SGIV ICP46 promoter, the plasmids pcDNA-012, pcDNA-039, pcDNA-057, pcDNA-072 alone or 4 combined plasmids (pcDNA012 + pcDNA-039 + pcDNA-057 + pcDNA-072) were cotransfected with P-22 and pRL-TK into GS cells, respectively. Vector pcDNA3.1/His A was used as negative control. At $24 \mathrm{~h}$ after the transfection, cells were infected with SGIV and harvested at $6 \mathrm{~h}$ p.i. for promoter analysis. The co-transfected cells without SGIV infection were also harvested at the same time for luciferase reporter assays.

\section{Determination of VATT binding site}

To determine the VATT binding site on the SGIV ICP46 promoter, the 64 bp sequence of probe $\mathrm{X}$ were divided into five probes which were overlapped each other continuously (Table 4). After incubated with the protein extraction from purified SGIV virion, the EMSA were performed using Non-Radioactive EMSA Kits (Viagene Biotech, Changzhou, China) following the manufacturer's protocol.

\section{Results}

SGIV ICP46 has short 5'-UTR and a potential DPE

To determine the TSS of SGIV ICP46, 5' RACE analysis was performed using total RNA extracted from GS cells at $12 \mathrm{~h}$ p.i. infected with SGIV. $5^{\prime}$ RACE was performed using three specific primers. PCR amplified fragments from $5^{\prime}$ ends were cloned and five individual SGIV ICP46 clones were sequenced. Data analysis showed that all sequences were identical and the TSS was at the G located $21 \mathrm{nt}$ upstream of the TIS (Fig. 1). The 5'-UTR of SGIV ICP46 was found to be short and only $20 \mathrm{nt}$ long. The core promoter elements analysis of SGIV ICP46 showed that no TATA-box was found within 94 nt upstream of TSS and no CAAT-box was found within $125 \mathrm{nt}$ upstream of TSS. However a potential DPE, AGACA, was found at +36 to +39 nt downstream of the TSS (Fig. 1). According to the $200 \mathrm{nt} 5$ '-flanking sequences of SGIV ICP46 and other 13 iridovirus ICP46s, three of the five genera of Iridoviridae were found to have presumptive DPE, they are Ranavirus,
Lymphocystivirus and Megalocytivirus (Table 1). Senven presumptive DPE were found in SGIV, GIV, LCDV-C, LCDV-SA, ISKNV, OSGIV and RBIV (Table 1, Fig. 2). ICP46s of SGIV, GIV, ISKNV, OSGIV and RBIV did not contain a classical TATA-box at the putative location (about - 30 nt to TSS), while ICP46s of LCDV-C and LCDV-SA contained both TATA-box and DPE motif (Table 1, Fig. 2).

\section{SGIV ICP46 core promoter includes -22 to $+42 \mathrm{nt}$ to the TSS}

To identify the sequences important for the SGIV ICP46 promoter activity, a series of mutants with progressive $5^{\prime}$ deletions were cloned in front of firefly luciferase reporter gene. To prevent loss of promoter activity in case the promoter region would extend over the TIS, a small $5^{\prime}$ part of the open reading frame (ORF) of SGIV ICP46 (about $40 \mathrm{nt}$ ) was included as well. The resulting plasmids were transfected to GS cells together with pRL-TK as a control plasmid to correct for variations in transfection efficiency. Luciferase reporter assays showed that the luciferase activity was markedly increased after transfected the promoter reporter plasmids P-3247, P-2180, P-1535, P-1159 and P649 comparing with the negative control plasmid pGL4.17, and the luciferase level of these five constructs had no significantly difference (Fig. 3a). The results indicated that the promoter region of SGIV ICP46 may locate between positions -649 to +44 .

To further narrow the core promoter region, more promoter deletions (P-559, P-502, P-442, P-360, P-279, P-196, P-136, P-82 and P-22) were used for luciferase activity assay. The results revealed that even the shortest deletion of -22 to +42 still had the transcriptional effects with regard to luciferase activity (Fig. 3b), which demonstrated that a major determinant for SGIV ICP46 promoter activity is located approximately between positions -22 and +42 .

After deletion of the key promoter region $(-22$ to +42 relative to the +1 TSS) from P-196, the levels of luciferase activity of P- $\Delta 196$ markedly reduced in SGIV-infected GS cells (Fig. 3c). This reduction in luciferase

Table 3 Primers used for the construction of recombinant eukaryotic expression plasmids

\begin{tabular}{lcc}
\hline Primer Name & \multicolumn{1}{c}{ Sequence 5'-3' } & Restriction Enzyme \\
\hline pcDNA-012F & 5'-CGGGATCCATGGTGACTGTCAAAGAACTTCAAG -3' & BamHI \\
pcDNA-012R & 5'-CGGAATTCCTAAAATCCGAGCGCGGACAAGATG -3' & EcoRI \\
pcDNA-039F & 5'-GA_GATCTATGGCTGATAATCTGAGCAACGTATG -3' & BglII \\
pcDNA-039R & 5'-CCGCTCGAGTTAAAATTCGTATCTATCGATGAG-3 & XhoI \\
pcDNA-057F & 5'-CCGCTCGAGTATGATTGTCACAATCAACGACAAATC -3' & XhoI \\
pcDNA-057R & 5'-TGCTCTAGATCACACTAAAAGAGAAACGTATTGC-3' & XbaI \\
pcDNA-072F & 5'-CGGGATCCATGACTTGTACAACGGGTGCTGGCG -3' & BamHI \\
pcDNA-072R & 5'-CCGCTCGAGTTACAAGATAGGGAACCCCATGGAAC-3' & XhoI \\
\hline
\end{tabular}

Restriction sites were added to the gene specific SGIV ICP46 primers to assist cloning into the eukaryotic expression plasmids pcDNA3.1/His A; The underline shows the restriction enzyme 
Table 4 The probe used for defining the VATT binding site by EMSA

\begin{tabular}{|c|c|}
\hline Name & Sequence \\
\hline probe $\mathrm{X}$ & 5'-GCGCAAACTCGGAACAAAAATCGCCCTTGTGGAAGATTTAAAAATGGCTTTCGTCACAGACAAG-3' \\
\hline probe 1 & 5'-GCGCAAACTCGGAACAAAAATCG-3' \\
\hline probe 2 & 5'-ACAAAAATCGCCCTTGTGGA-3' \\
\hline probe 3 & 5'-CCCTTGTGGAAGATTTAAAA-3' \\
\hline probe 4 & 5'-AGATTTAAAAATGGCTTTCG-3' \\
\hline probe 5 & 5'-ATGGCTTTCGTCACAGACAAG-3' \\
\hline
\end{tabular}

Framed sequence represent potential downstream core promoter element (DPE)

The determined binding site of virion-associated transcriptional transactivator (VATT) on SGIV ICP46 promoter are underlined

activity for P- $\Delta 196$ confirmed that the 64 nt-region from -22 to +42 is the core region of SGIV ICP46 promoter.

VATT are needed to activate the SGIV ICP46 promoter The heat-inactivated SGIV has denatured virion-associated proteins and replicable DNA, while the UV-inactivated SGIV has active virion-associated proteins and damaged DNA. Comparing with the mock-infected cells, luciferase activities were markedly increased after infected with the infectious SGIV and UV-inactivated SGIV in the P-22 transfected GS cells, while the luciferase activity of the P-22 transfected cells infected with heat-inactivated SGIV was similar with the mock-infected cells (Fig. 4a). These results suggested that the transcription of SGIV ICP46 required SGIV infection and the SGIV ICP46 promoter was activated by certain heat-labile VATT.
To analysis whether the newly synthesized viral proteins can influence the activity of SGIV ICP46 promoter, P-22 transfected GS cells were treated with CHX and AraC, respectively. The luciferase reporter assay showed that $\mathrm{CHX}$ and Ara had no significant effect on the activity of SGIV ICP46 promoter (Fig. 4b). CHX can block translation, allow only IE viral mRNAs to be synthesized and prevent the expression of SGIV E genes and L genes in host cells, while AraC is the virus DNA synthesis inhibitor and can restrain the the expression of SGIV L genes. The results indicated that no SGIV early proteins or late proteins involved in the regulation of SGIV ICP46 promoter.

\section{VATTs that interact with SGIV ICP46 promoter are VP12, VP39, VP57 and MCP}

The EMSA probe, biotin-labled probe $\mathrm{X}$, was design and synthesis according to the sequence of SGIV

$$
\begin{aligned}
& \text {-300 AACTCACAGACCAATGCATTCCCATCGTACTCTTCAAAATGAAAGA } \\
& \text { GTACGATTTTGCAGAAATGGAAGCCAACAAAATATACAGCGAGTACG } \\
& \text { AAATGATAAAGTACAGAGATTGGCTCGAGTATTATACCGTTTAAAAA } \\
& \text { GACTATCACCAATTGGCAGTGTCCAAATTGCAAAAGTTAATATAATT } \\
& \text { GAGCATTTCCGATATTTTAACCTTTTAAAAGGTTAAAATATCGTGTAA } \\
& \text { AAAAACTTGATTAGCGAGTTTGCGCAAACTCGGAACAAAAATCGCCC } \\
& \text { +22++36 } \\
& \text { TTGTGGAAGATTTAAAAATGGCTTTCGTCACAGACAAGCGAGAAA }
\end{aligned}
$$

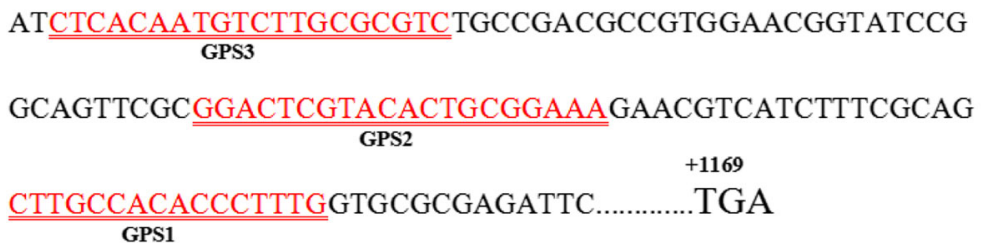

Fig. 1 Determination of the $5^{\prime}$ end of the SGIV ICP46 gene transcripts by $5^{\prime}$ RACE analysis. The transcription start site (TSS) is position +1 . Sequence printed with shadow shows the $5^{\prime}$-untranslated region (5'-UTR). Primers used for $5^{\prime}$ RACE analysis are indicated as GSP1, GSP2, and GSP3 with double underline. Total ORF of SGIV ICP46 is $1149 \mathrm{nt}$. Bold sequences represent the TATA-box and CAAT-box like sequences. Framed sequence represent potential downstream promoter element (DPE). Underlined sequence show the binding region with virion-associated transcriptional transactivator (VATT) 


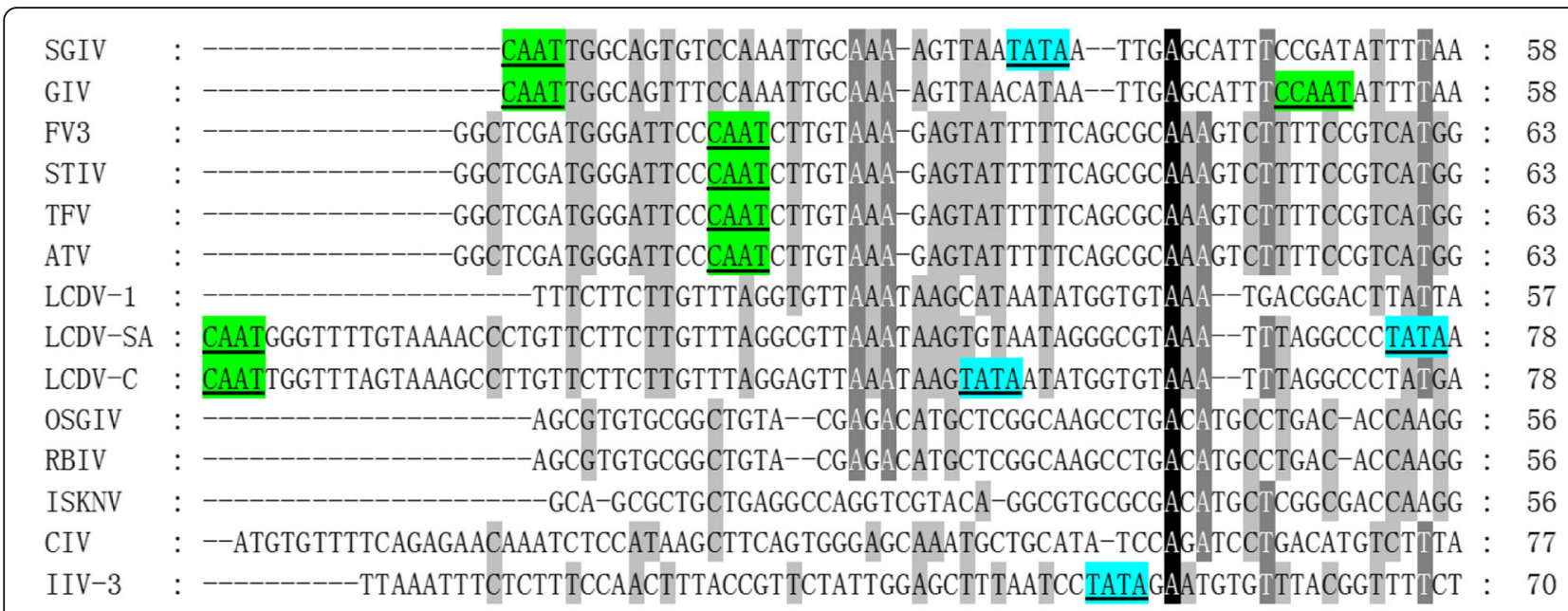

SGIV : CCTTTTAAAAGGITAAAATATCGTGTAAAAAAACTTGATTAGCG--AGTTTGCGCAAACTCGGAACAAAAATCGCCCTIT : 136 GIV : CCTTTTAAAAAGGITAAAATATCGTGTAAAAAAACTTGATMAGCG--AGTTTGCGCAAACTCGGAACAAAAATCGCCCTIG : 136 FV3 : GTCCTCCAT-GAIIGGAAATAAAACATGAAGTGTCC-GTTTGCTGC-AAAACGGGTCTTITTGGAGTCAC--ITGTCTCIG : 138 STIV : GTCCTCCAT-GAIIGGAAATAAAACATGAAGTGTCC-GTTIGCTGC-AAAACGGGTCTTITTGGAGTCAC--ITGTCTCIIG : 138 TFV : GTCCTCCAT-GAIIGGAAATAAAACATGAAGTGTCC-GTTTGTCGC-AAAACGGGTCTTTTTTGGAGTCAC--ITGTCTCTG : 138 ATV : GTCCTCCAT-GAIIGAAAATAAAACATGAAGTGTCC-GTTIGCCAC-AAAACGGGTCTTITCGGAGTCAC--ITGTCTCII : 138 LCDV-1 : -TCTTCCATGGATATAAAITGGTTTTATATAAAT-CAATCGTTT---GCATTTTTGTTITTGTTTTAAAATITATGAAIC : 132 LCDV-SA : -TTTTCCAAGGATATAAAITGTTTTTATAGAGATC-GATCGTCG---ACATTTTTATTIT------AAAATITATGAATC : 147

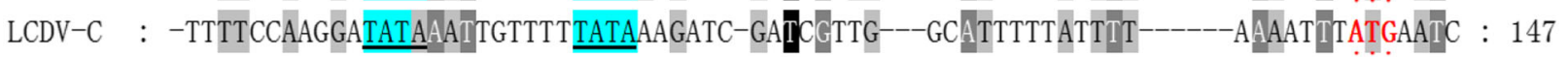
OSGIV : CCCTGTGCTATGIGGTGCGCACCATCGCCGGGTCACACTIGCCACTGGCATAAGCACCIC--ATTTGGGTGTCCCAAAIG : 134 RBIV : CCCTGTGCTATGIGGTGCGCACCATCGCCGGGTCACACTITCCACTGGCATAAGCACCIC--ATTTGGGTGICCCAAAIG : 134 ISKNV : CCTTGTGCTATGIIGGTGCGCGCCATCGCCGGGTAGCACTITCCGCCGGCATAAGCACCIC--ATTTGGATGCCCCAAATG : 134 CIV : ----TTAATAAG ITAAATIAGTTTAGTTAAACGGAAAATIGAAGC---TACTAAAAGGITTTATTCAAA-- TAATTAAIG : 148 IIV-3 : GCCTCGTCTGGTCCATAGIIGACGCACAAGCGCAGAAATTIGAAAAGAAAAAATTAAATAATAAAGTAAATTAAACTCAAA : 150

SGIV : TGGAAGAITTAAAA-ATGGCTITCGTC-ACAGACAAGCGAGAAAATCTCACAATGTCTTGCGCGTC----- : 200

GIV : TGGAAGACTTAAAAAATGGCTTTCGTC-ACAGACAAGCGAGAAAATCTCACAATGTCTTGCGCGTC---- : 201

FV3 : ACAAATCITAACATGGCAAACITTTGTG-ACAGACTCTCGCAATGGGCTCACCATCTCTTGCGC------ : 200

STIV : ACAAATCTTAACATGGCAAACTTTGTG-ACAGACTCTCGCAATGGACTCACCATCTCTTGCGC------- : 200

TFV : ACAAATCITAACATGGCAAACITTGTG-ACAGACTCTCGCAATGGACTCACCATCTCTTGCGC----- : 200

ATV : ACAAATCITAACATGGCAAACTTTGTG-ACAGACTCTCGCAACGGGCTCACCATCTCTTGCGC------- : 200

LCDV-1 : TCAA--TITCAAAAACCGATGITAATA-ATTAACCGGCTTTATGGATTCTCACTCGTTCAAAACAACTCAA : 200

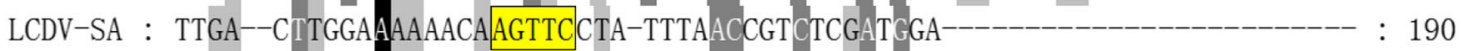
LCDV-C : TTGA--TITCAAAAAAACA AGTTCT GA-TTTAACCGTCTCGATGGA ${ }^{--}-{ }_{-1}$ OSGIV : AGGTG RBIV : AGGTGTATATATAAAAATGGITGAGCAGACA GATGTCCGTGACGACCTGTGCATCATCAATGATGG---- : 200 ISKNV : AGGTGTATATATAAAAATGGGCGAGCAGACAGATGTCAGTGACGACCTGTGCATCATCAATGATGG----- : 200

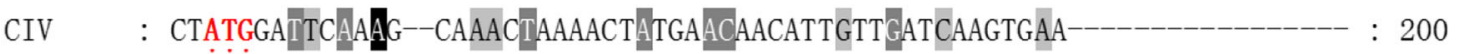

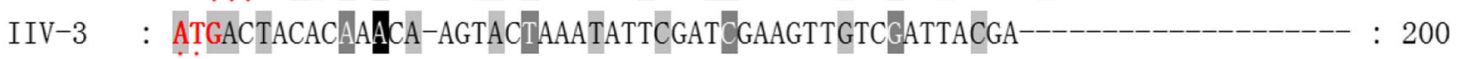

Fig. 2 (See legend on next page.) 
(See figure on previous page.)

Fig. 2 The core promoter elements analysis of SGIV ICP46 and other 13 iridovirus ICP46s. About 200 nucleotides (nt) flanking sequence of the translation initiation site (TIS) from SGIV ICP46 and other 13 iridovirus ICP46s were chosen, their GenBank accession numbers show in Table 1. Multiple nucleic acids sequence alignment of 14 iridovirus ICP46s was performed. The highly conserved residues in all sequences are indicated over a black background, sequences with high identities in one position are highlighted in dark grey or grey shadow. The TATA-box and CAATbox like sequences are underlined. The the transcription start site (TSS) and the TIS are emphasized with symbol "*" and "." respectively. Framed sequence represent potential downstream promoter element (DPE)

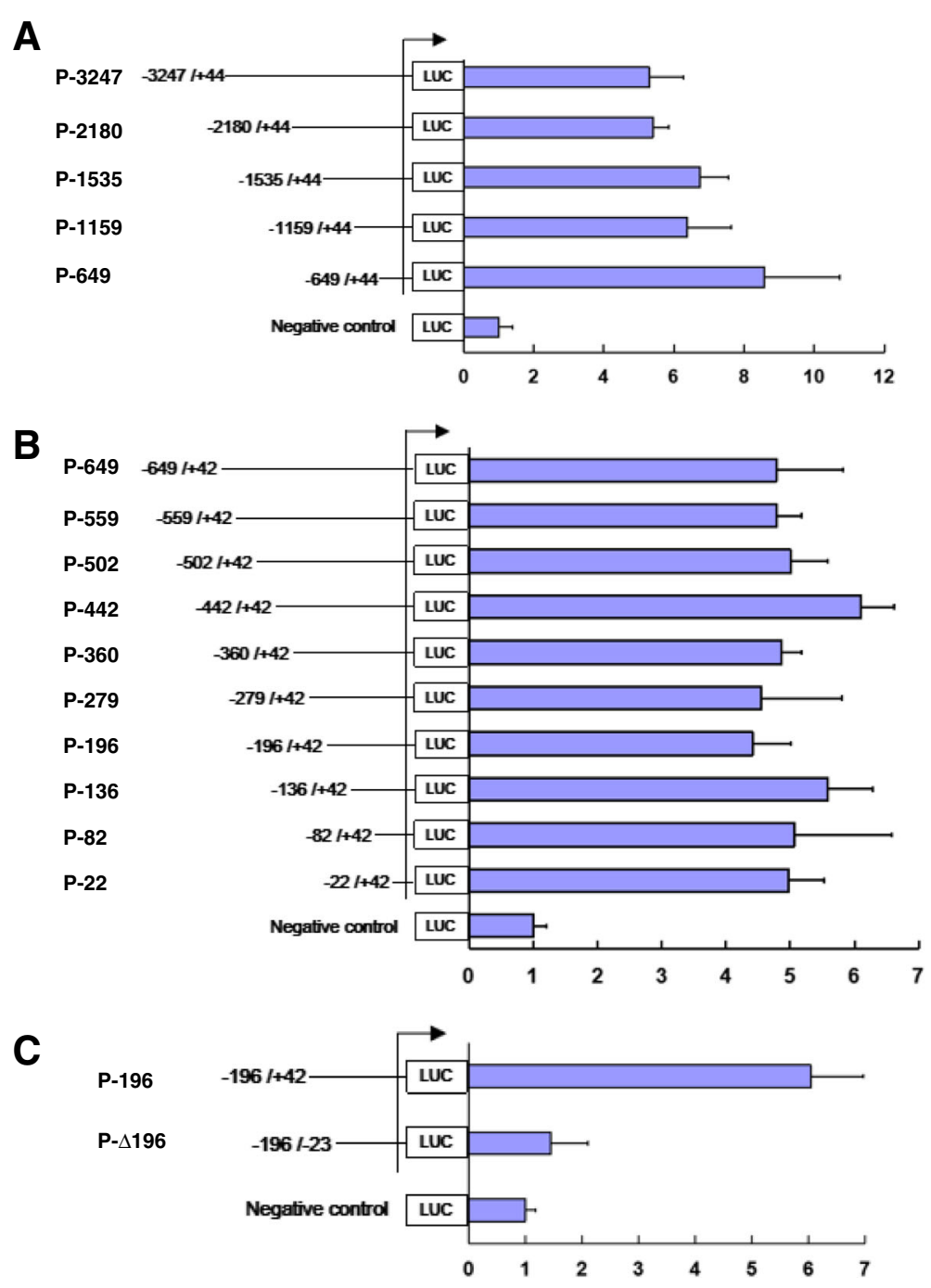

Fig. 3 Deletion mutants of SGIV ICP46 promoters. a Luciferase reporter assays of consecutive deletion mutants from -3247 to +44 . $\mathbf{b}$ Luciferase reporter assays of consecutive deletion mutants from -649 to +42 . c Luciferase reporter assays of P-196 $(-196$ to +42$)$ and P- -196 (with -22 to + 42 deleted from P-196). DNA fragments decreasing in length and located upstream of the open reading frames for SGIV ICP46 was fused to a luciferase reporter gene. GS cells were transfected with these promoter constructs followed by SGIV infection at MOI of 2 at $24 \mathrm{~h}$ after transfection. Cells were harvested $6 \mathrm{~h}$ p.i. for luciferase reporter assays. Firefly luciferase activities were normalized based on the activity of Renilla luciferase. The mean Fluc/Rluc intensity of negative control was considered as 1. The plasmid numbers on the left side specify the beginning and end positions (TSS as +1 ) of deletion mutants. TSS are marked by arrows. Error bars show SD of three independent experiments 

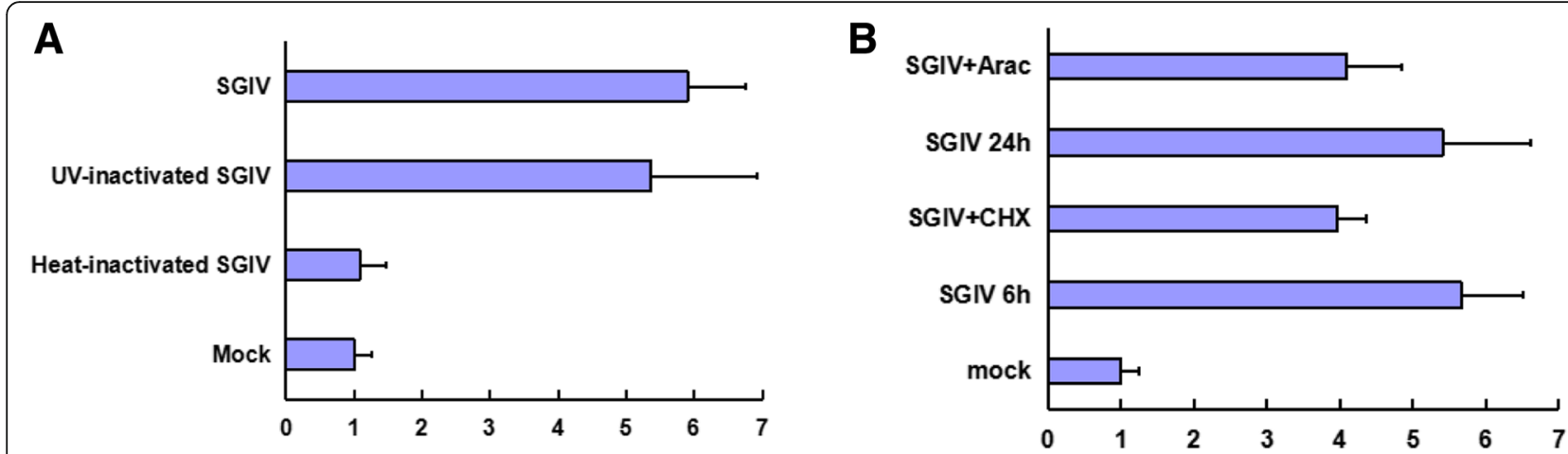

Fig. 4 Regulation of the SGIV ICP46 promoter. a The transcription of SGIV ICP46 requires SGIV infection and is activate by heat-labile virionassociated transcriptional transactivator (VATT). GS cells were transfected with P-22, which containing the core region of SGIV ICP46 promoter, and then the transfected cells were either mock infected or infected with infectious SGIV, heat-inactivated SGIV and UV-inactivated SGIV, respectively. $\mathbf{b}$ CHX and Ara has no significant effect on the activity of SGIV ICP46 promoter. GS cells were transfected with P-22 and then the transfected cells were pretreated with cycloheximide (CHX) or cytosine arabinofuranoside (AraC) for $1 \mathrm{~h}$ before and throughout the SGIV infection. CHX or AraC-pretreated cells were infected with SGIV, then harvested at 6 and $48 \mathrm{~h}$ p.i., respectively. The P-22 transfected GS cells infected with SGIV were collected at the same time points and served as control

ICP46 promoter $(-22$ to +42$)$. The protein extraction from GS, SGIV+GS, CHX + SGIV, AraC+SGIV cells and purified SGIV virion were used for EMSA analysis. The results show that all the protein extraction from GS, SGIV+GS, CHX + SGIV, AraC+SGIV cells and purified SGIV virion can combine with the probe $\mathrm{X}$ and form protein-DNA complexes. The band position of protein-DNA complexes from GS, SGIV+GS, CHX + SGIV and AraC+SGIV cells are basically the same, while the migration distance of protein-DNA complex from SGIV virion is further away from the sample holes (Fig. 5). The results suggested that the identified promoter region of SGIV ICP46 can interact with the transcription factors from both host cells and SGIV virion.

To Identify the VATT which may combine with SGIV ICP46 promoter and involve in the regulation of SGIV ICP46 promoter activity, DNA pull-down was conducted with the biotin-labled probe $\mathrm{X}$ and the protein extraction from GS, SGIV+GS, CHX + SGIV, AraC+SGIV cells and purified SGIV virion, respectively. The results of SDS-PAGE showed that the protein bands obtained by electrophoresis in GS, SGIV+GS, CHX + SGIV, AraC+SGIV cells were quite similar, and nine clear protein bands from SGIV+GS were selected for NanoLC-ESI-MS/MS analysis (Fig. 6 lane 5). For the protein extraction from purified SGIV virion, only two strong protein bands were observed (Fig. 6 lane 7). The mass spectrometry (MS) analysis showed that quite a few proteins from Epinephelus coioides were identified in the nine protein bands from SGIV+GS (data not shown), but no SGIV proteins were found might due to the low abundance. The MS data of the two DNA-binding protein bands (band A, B in Fig. 6) in SGIV virion sample are presented in Table 5, and four SGIV proteins that interacted with the SGIV ICP46 promoter were identified by MS. They are VP12, VP39, VP57 and major capsid protein (MCP) which are encoded by SGIV ORF012L, ORF039L, ORF057L and ORF072R, respectively.

\section{Effect of transient expression of VATTs on SGIV ICP46 promoter activity}

To verify the effect of the four identified VATTs on the activity of SGIV ICP46 promoter, four recombinant eukaryotic expression vectors (pcDNA-012, pcDNA-039, pcDNA-057 and pcDNA-072) were constructed, and proved to be successfully expressed in GS cells by RTPCR (Fig. 7a). In mock-infected samples, the luciferase activity exhibit similar low level after transfecting with pcDNA-012, pcDNA-039, pcDNA-057, pcDNA-072 alone or four plasmid combined comparing with the negative control plasmid pcDNA3.1/His A. The results showed that the expression of these four virus genes alone or in combination did not significantly affect the activity of the SGIV ICP46 promoter (Fig. 7b). Comparing with the mock-infected samples, the luciferase level increased markedly in all SGIV-infected samples. Together with SGIV infection, the luciferase activity in pcDNA-057 and combined plasmids transfected cells were slightly higher than that of pcDNA-012, pcDNA039, pcDNA-072 and pcDNA3.1/His A transfected cells.

\section{The promoter binding site with VATTs is "ATGGCTTTCG"}

Since the VATTs are involved in the activation of SGIV ICP46 promoter, the binding site with VATTs of the SGIV ICP46 promoter was defined. Probe $\mathrm{X}$ and probe 1-5 (Table 4) were incubated with SGIV virion extracts respectively and EMSA were performed, the results show that the band of DNA 


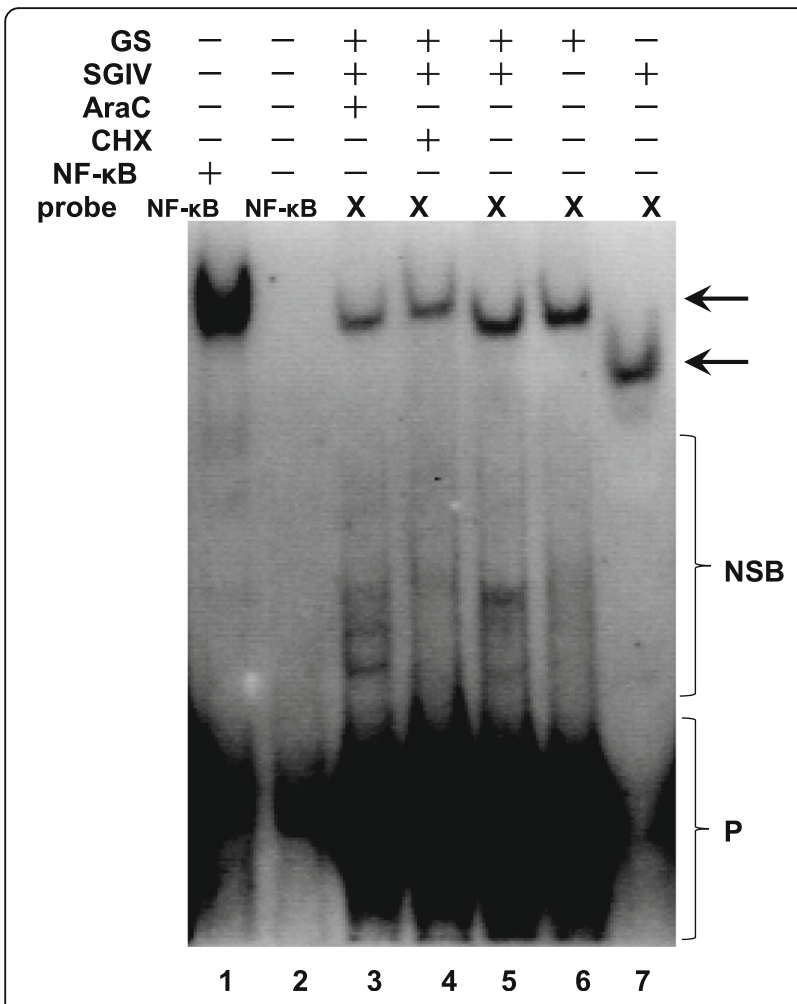

Fig. 5 Electrophoretic mobility shift assay. The whole protein extractions from AraC-pretreated and SGIV-infected GS cells (AraC+SGIV, lane 3), CHX-pretreated and SGIV-infected GS cells (CHX + SGIV, lane 4), SGIV-infected GS cells (SGIV+GS, lane 5), GS cells (GS, lane 6) and purified SGIV virion (SGIV, lane 7) were obtained for EMSA analysis with biotin-labeled probe $X$ that contains the sequence of SGIV ICP46 promoter. Incubated with biotin-labeled probe $N F_{K B}$, the nuclear extracts with activated NFKB was used as positive control (lane 1) and nuclear extracts without activated NFKB (lane 2) was used as negative control. Arrow show the DNA binding proteins; NSB, non-specific binding; P, free biotin labeled probe

binding protein of SGIV can be found in lane 3, lane 7 and lane 8 (Fig. 8), which mean that probe $\mathrm{X}$, probe 4 and probe 5 can form protein-DNA complexes with SGIV VATTs. Probe $\mathrm{X}$ is $64 \mathrm{nt}$ and has been proved can form protein-DNA complexes with SGIV VATTs (Fig. 5, lane7). Probe 4 and probe 5 are parts of Probe $\mathrm{X}$ and overlapped each other. The sequence of probe 4 is $5^{\prime}$-AGATTTAAAAATGGCTTT CG- ${ }^{\prime}$ and probe 5 is $5^{\prime}$-ATGGCTTTCGTCACAGACAAG-3' (the overlapped part are underlined and the presumptive DPE displays in bold type). Taken together, it can be concluded that the overlapped squence of probe 4 and probe 5, ATGGCTTTCG, is the binding site with VATTs on SGIV ICP46 promoter.

\section{Discussion}

The TSS of SGIV ICP46 was at the G located $21 \mathrm{nt}$ upstream of the TIS. It has been proved that the

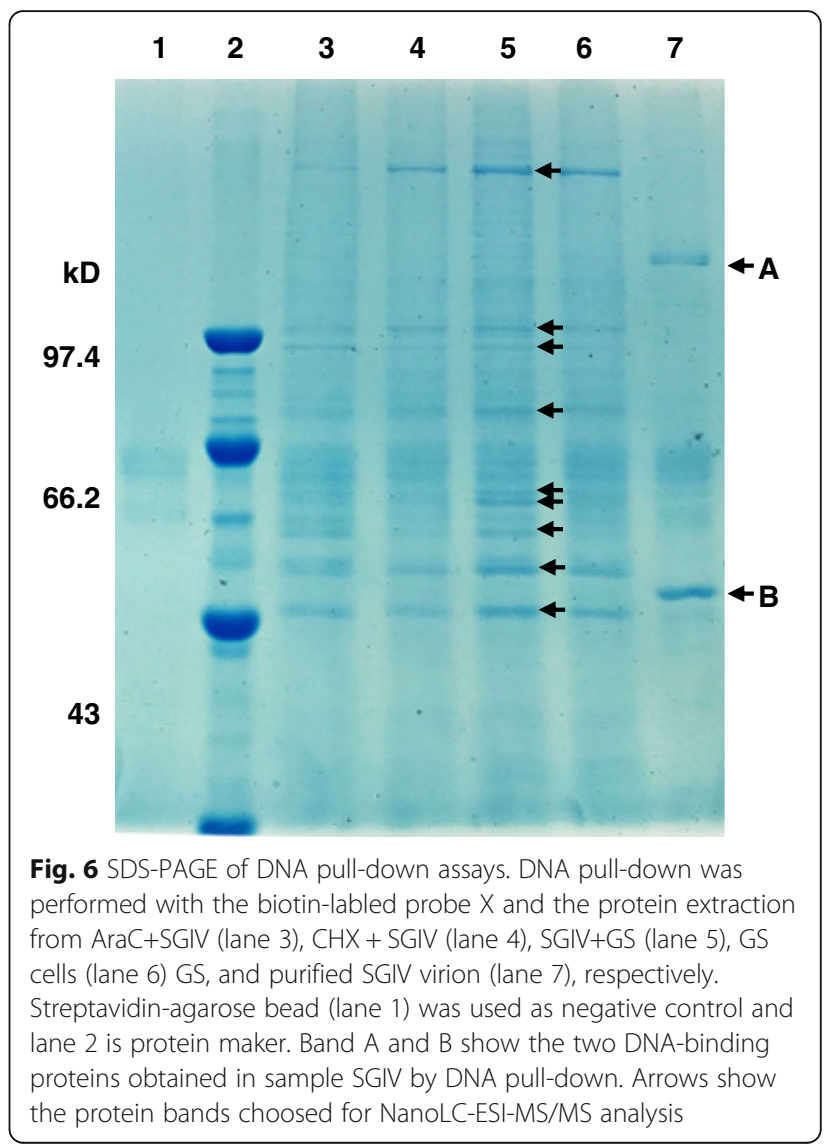

RNA polymerases preferentially initiate transcription with a purine residue $[20,21]$. Our study showed that SGIV ICP46 has a short 5' -untranslated regions (5'UTR) of $20 \mathrm{nt}$. Previous studies revealed that transcripts in the Iridoviridae family may have short upstream 5'-UTR. For example the short 5'-UTR were found to be a common property for genes of Chilo iridescent virus (CIV), the CIV ORF012, CIV MCP and CIV DNApol genes have 35, 14 and $30 \mathrm{nt} 5^{\prime}$ UTR, respectively [22, 23]. Furthermore, it was reported that the $5^{\prime}$-UTR were generally found to be short in FV3 [24]. The Bohle iridovirus (BIV) ICP 46, which promoter was identical to that of FV3 ICP46, has 30 nt 5 '-UTR [13].

The location of typical TATA-box and CAAT-box is about -30 and -80 relative to the TSS respectively, while the core promoter elements analysis of SGIV ICP46 showed that no TATA-box and CAATbox were found within $94 \mathrm{nt}$ and $125 \mathrm{nt}$ upstream of TSS, it seems that SGIV ICP46 promoter is a TATA-less and CAAT-less promoter. Meanwhile, a potential DPE was found at +36 to +39 nt downstream of the TSS. DPE is one of the core promoter element and plays an important role in the initiation 
Table 5 Identification of DNA-binding proteins that interact with the SGIV ICP46 promoter by MS

\begin{tabular}{lllllllll}
\hline Band & Hits & Protein Mass & No. of Peptide & Species / Gene / Protein & Link & Relative Abundance & Probability & Accession no. \\
\hline A & 1 & 117582.48 & 20 & SGIV / ORF012L / VP12 & Q5YFQ3 & $47.6 \%$ & $99.0 \%$ & AAS18027.1 \\
& 2 & 119868.84 & 35 & SGIV / ORF039L / VP39 & Q5YFM6 & $42.7 \%$ & $99.0 \%$ & AAS18054.1 \\
& 3 & 132084.14 & 9 & SGIV / ORF057L / VP57 & Q5YFK8 & $9.6 \%$ & $99.0 \%$ & AAS18072.1 \\
& 4 & 48126.83 & 1 & SGIV / ORF072R / MCP & A0A1B3B4Y6 & $0.1 \%$ & $87.2 \%$ & AAS18087.1 \\
B & 1 & 50844.09 & 146 & SGIV / ORF072R / MCP & Q5YFJ3 & $99.2 \%$ & $99.0 \%$ & AAS18087.1 \\
& 2 & 119868.84 & 2 & SGIV / ORF039L / VP39 & Q5YFM6 & $0.1 \%$ & $84.7 \%$ & AAS18054.1 \\
\hline
\end{tabular}

Protein Mass: Theoretical molecular weight of protein

No. of Peptide: Total number of identified peptide

Link: protein information link to https://www.uniprot.org/uniprot

Relative Abundance: Relative abundance of protein calculated by Label-free method

Accession no. GenBank accession numbers

of gene transcription by RNA polymerase II, the DPE functions cooperatively with the initiator (Inr) to bind to TFIID and directs accurate and efficient initiation of transcription in many TATA-less promoters $[25,26]$.
The DPE is usually located about $30 \mathrm{nt}$ downstream of the TSS and most commonly found in TATA-less promoters [27]. It has been reported that the promoters of virus genes may contain DPE motif which is implicated in the control of promoter activity and gene expression.
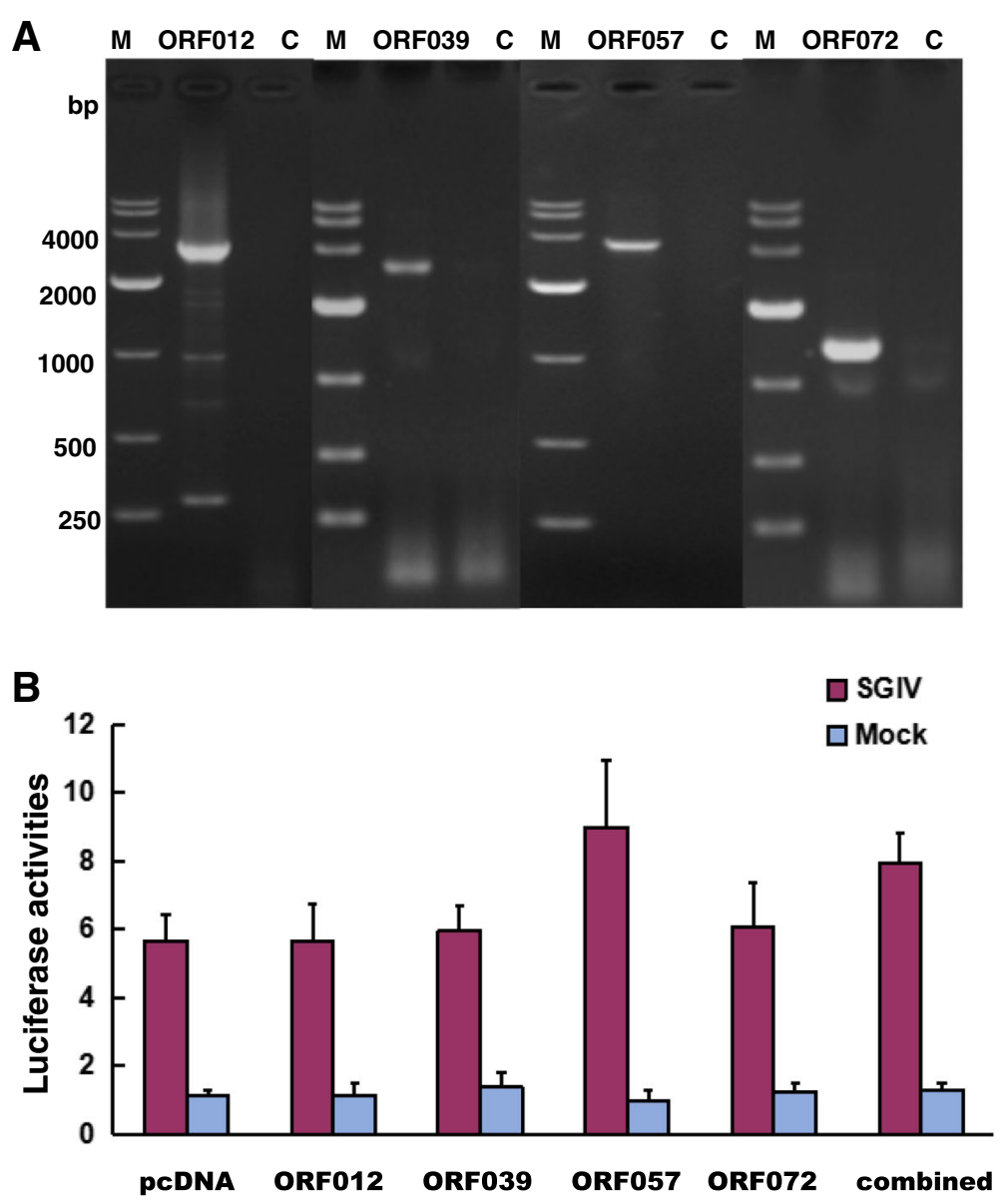

Fig. 7 Effect on SGIV ICP46 promoter activity by transient expression of four VATTs. (a) Expression of four VATTs in GS cells verified by RT-PCR after transfected with pcDNA-012, pcDNA-039, pcDNA-057 and pcDNA-072 at $24 \mathrm{~h}$ post tansfection . lanes M, $10 \mathrm{~kb}$ DNA ladder; Lanes C, negtive control. (b) The luciferase reporter assays after co-transfection with pcDNA-012, pcDNA-039, pcDNA-057, pcDNA-072 alone or 4 plasmids combined. At $24 \mathrm{~h}$ post transfection, cells were infected with SGIV and harvested at $6 \mathrm{~h}$ p.i.. The co-transfected cells without SGIV infection were harvested at the same time for luciferase reporter assays. Firefly luciferase activities were normalized based on the activity of Renilla luciferase. The mean Fluc/Rluc intensity of negative control was considered as 1 


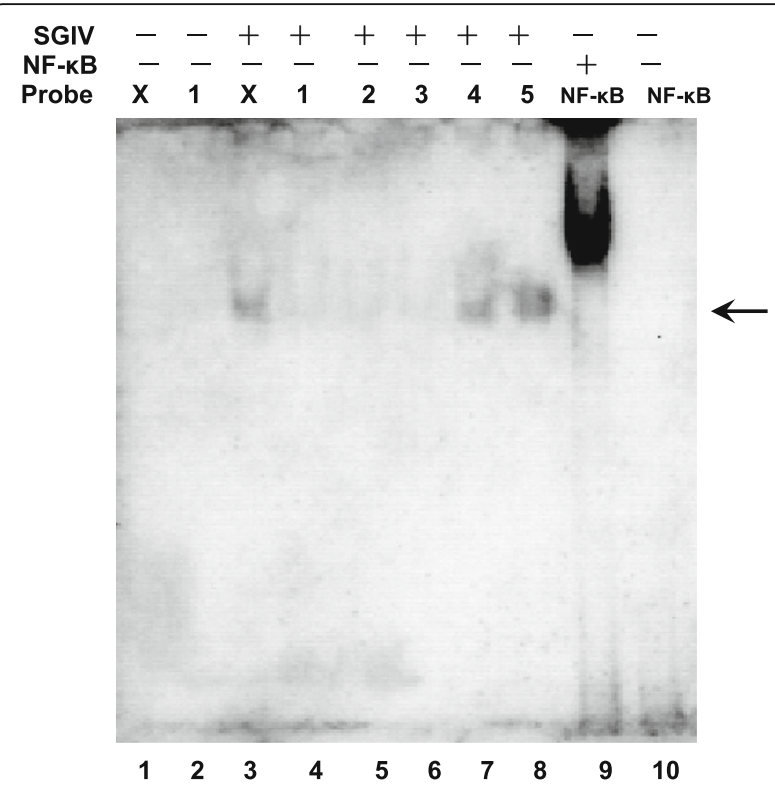

Fig. 8 Determination of VATT binding site on SGIV ICP46 promoter by EMSA. Probe $X$ that contains the 64 bp SGIV ICP46 promoter were divided into five probes which were overlapped each other continuously (probe 1-5 in Table 3). After incubated with the protein extraction from purified SGIV virion, the EMSA were performed. Arrow show the DNA binding proteins of SGIV. Incubated with biotin-labeled probe NFKB, the nuclear extracts with activated NFKB was used as positive control (lane 9) and nuclear extracts without activated NFKB (lane 10) was used as negative control

For example, the P38 of parvovirus and minute virus of mice (MVM) [28, 29], HSV-1 late genes [30], and the bro-c gene from Bombyx mori nucleopolyhedrovirus (BmNPV) [31] were all proved to contain DPE motif in their promoters. The bro-c gene of BmNPV has a pentanucleotide sequence CACGC located 30 nt downstream of the TSS and is essential for bro-c promoter activation. It reasonable to infer that the presumptive DPE of SGIV ICP46 may play an important role in the promoter activation and the initiation of gene transcription.

In addition, the core promoter elements analysis of 14 iridovirus ICP46s revealed that three of the five genera of Iridoviridae have potential DPE, they are Ranavirus, Lymphocystivirus and Megalocytivirus. Interestingly, Ranavirus, Lymphocystivirus and Megalocytivirus are exactly the three genera which can infect teleost fishes in family Iridoviridae. Seven fish pathogenic iridoviruses (SGIV, GIV, LCDV-C, LCDV-SA, ISKNV, OSGIV and RBIV) were found to have presumptive DPE. Although belong to the same genus Ranavirus as SGIV and GIV, no DPE were found in FV3, STIV, ATV and TFV, which are infectious to amphibians and reptiles. It is uncertain whether the presumptive DPE of ICP46 from fish pathogenic iridoviruses is associated with the transcription characteristic in teleost fishes. The DPE as core promoter elements for ICP46s of fish infectious iridovirus still need to be verified and studied in further research.

The promoter analysis found that the core regions of SGIV ICP46 promoter include sequence $22 \mathrm{nt}$ upstream and $42 \mathrm{nt}$ downstream of the TSS. Previous research about FV3 ICP46 showed that the promoter was from $291 \mathrm{nt}$ upstream to $195 \mathrm{nt}$ downstream of TTS, and found that the FV3 ICP46 was overexpressed in the presence of CHX and inferred that certain early proteins have negative control over FV3 ICP46 tanscription [12]. Different with FV3 ICP46, both $\mathrm{CHX}$ and Ara had no significant effects on the activity of SGIV ICP46 promoter, and indicated that the newly synthesized SGIV early proteins and late proteins in host cells did not markedly affect the activity of SGIV ICP46 promoter. Similar to FV3 ICP46, heat-labile VATTs were needed for activating the SGIV ICP46 promoter. No previous studies have identified the VATTs involved in ICP46 promoter activation. For the first time, four VATTs (VP12, VP39, VP57 and MCP) that can combine with the SGIV ICP46 promoter were identified by EMSA and DNA pull-down in this study. Coincidentally, VP12, VP39, VP57 and MCP have been identified to be virion-associated proteins in the SGIV viral proteome by 1 DE-MALDI and LC-MALDI workflow [32]. VP39, VP57 and MCP are Iridoviridae core proteins, and VP12 is a conserved iridovirus protein exist in genera Ranavirus and Lymphocystivirus. The function of VP12 is still unknown [19]. VP39 is a viral envelope protein and predicted to be a serine-threonine protein kinase, neutralization assays revealed that anti-SGIV VP39 serum could block SGIV infection [33]. Iridovirus MCP has been proved to be essential for virus replication by siRNA-based knockdown and anti-MCP serum-based neutralization test [34]. A homologue of SGIV VP57, CIV $295 \mathrm{~L}$, is predicted to bind the viral DNA or DNA-binding proteins, has a function in the viral DNA replication or virus gene transcription [35]. Both SGIV VP57 and CIV $295 \mathrm{~L}$ have a predicted nuclear localization signal. The transcription of iridovirus IE genes are catalyzed by host polymerase II and VATTs may modify cellular polymerase II, interact with cellular transcription factors, or alter the DNA template and permit transcription of IE messages [3].

Co-transfection and luciferase reporter assays showed that the transient expression of four VATTs alone or combined did not significantly affect the activity of the SGIV ICP46 promoter without SGIV infection. The virion protein composition of five iridoviruses have been determined, including SGIV [32, 33, 36-38], these studies showed that iridovirus virions contain 40 to 64 
virion-associated proteins and the protein-protein interactions between virion-associated proteins are required for viral assembly and other important functions throughout the course of infection [35]. It reasonable to infer that not only the presence of four VATTs but also the protein-protein interactions and structural connection existing among VATTs were needed for the transactivation of SGIV ICP46. The CIV interactome study have identified the interactions between virus structural proteins using the yeast two-hybrid system, and revealed that proteins $274 \mathrm{~L}$ and $295 \mathrm{~L}$ show indirect interactions with each other and protein $274 \mathrm{~L}$ is interacting with proteins encoded by seven different ORFs [35]. Interestingly, SGIV VP57 and SGIV MCP are just the homologues of CIV proteins $295 \mathrm{~L}$ and $274 \mathrm{~L}$, respectively. Moreover, the virus promoters requires the synergistic activation of multiple transcription factors, including host and viral transcription factor, as well as various signaling pathway proteins interacting with these transcription factors [39-41]. Besides the four VATTs, many transcription factors from host cells also can combine with the SGIV ICP46 promoter and involved in the initation of gene transcription. Whether the network of protein-protein interactions existing among four VATTs of SGIV ICP46 promoter and the detailed mechanism about how VATTs activate the SGIV ICP46 promoter still need further studies.

The VATT binding site was defined by EMSA and reavealed that the 10-base DNA sequence "ATGG CTTTCG" between the TSS and the presumptive DPE is the binding site with VATTs. Transcription is a complicated process which involves the interactions of promoter elements with multiple transcription factors. The specific interactions rely not only on the specific sequence recognition but also on certain spatial arrangement of the factors in a complex [42]. The study about BmNPV bro-c promoter showed that the spacing between the TSS and DPE were also required for promoter activation [31]. On the SGIV ICP46 promoter, the 10base DNA sequence "ATGGCTTTCG" is just between the TSS and presumptive DPE, and was proved to be the binding site of VATTs, it is reasonable to infer that the binding of VATTs with promoters helps to initiate the transcription of SGIV ICP46. In theory, interrupting the bind between VATTs and their binding site can effectively prevent the transcription of SGIV ICP46, then affect the temporal gene expression of SGIV and block the ordered cascade of viral life events, thus providing a new strategy for anti-virus infection.

\section{Conclusion}

In conclusion, our present study found that the core region of SGIV ICP46 promoter locate from -22 to +42 nt relative to the TSS and probably is a TATA-less and
DPE-containing promoter. This study also demonstrated that VATTs are required to initiate SGIV ICP46 transcription and the further molecular identities of VATTs are VP12, VP39, VP57 and MCP. Further examination revealed the binding site of VATTs interact with SGIV ICP46 promoter is ATGGCTTTCG between the TSS and presumptive DPE.

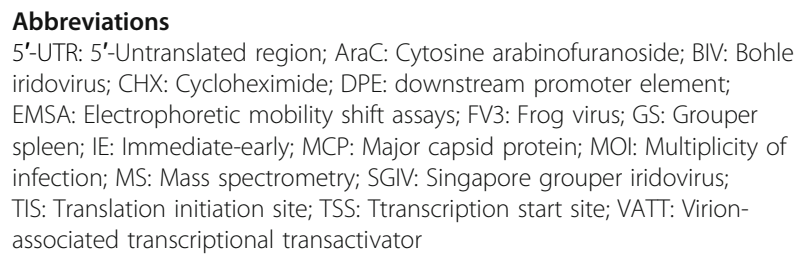

\section{Acknowledgements}

The authors would like to thank Prof. Qi-Wei Qin (College of Marine Sciences, South China Agricultural University, Guangdong, China) for kindly providing the Singapore grouper iridovirus and GS cells.

\section{Authors' contributions}

LQX and YSL conceived and designed this study. LQX, JLC and HLZ contributed to the plasmid construction and cell experiments. LQX, JLC, HLZ, $J C, Z S$ and YSL helped with the laboratory experiments and interpreted the data. LQX prepared the manuscript. YSL reviewed and critically revised the manuscript. All authors read and approved the final manuscript.

\section{Funding}

This work was supported by National Natural Science Foundation of China (41406172, U1401211, 31402335), Natural Science Foundation of Guangdong Province (2014A030313602, 2017A030313179), Shenzhen science and technology project (JCYJ20170306161613251), Shenzhen Dapeng New District special fund for industry development (KY20160207, PT201901-06), Research Projects of Guangdong Ocean University's Top-ranking Discipline Construction (231419017) and Natural Science Foundation of Guangdong Ocean University (C17377, C13454).

Availability of data and materials Not applicable.

Ethics approval and consent to participate Not applicable.

\section{Consent for publication}

Not applicable.

\section{Competing interests}

The authors have no conflicts of interest to declare.

\footnotetext{
Author details

${ }^{1}$ Shenzhen Institute of Guangdong Ocean University, Shenzhen City, Guangdong, China. ${ }^{2}$ College of Fisheries, Guangdong Ocean University, Zhanjiang City, Guangdong, China. ${ }^{3}$ Guangdong Provincial Engineering Research Center for Aquatic Animal Health Assessment, Shenzhen Public Service Platform for Evaluation of Marine Economic Animal Seedings, Shenzhen City, Guangdong, China. ${ }^{4}$ Guangdong Provincial Key Laboratory of Pathogenic Biology and Epidemiology for Aquatic Economic Animal, Guangdong Ocean University, Zhanjiang City, Guangdong, China. ${ }^{5}$ College of Marine Sciences, South China Agricultural University, Guangzhou City, Guangdong, China.
} 
Received: 4 June 2019 Accepted: 5 August 2019 Published online: 03 September 2019

\section{References}

1. Chinchar VG, Waltzek TB, Subramaniam K. Ranaviruses and other members of the family, Iridoviridae: their place in the virosphere. Virol. 2017;511:259-71.

2. Huang $Y H$, Huang $X H$, Wang SW, Yu YP, Ni SW, Qin QW. Soft-shelled turtle iridovirus enters cells via cholesterol-dependent, clathrin-mediated endocytosis as well as macropinocytosis. Arch Virol. 2018;163:3023-33.

3. Chinchar VG, Hyatt A, Miyazaki T, Williams T. Family Iridoviridae: poor viral relations no longer. Curr Top Microbiol Immunol. 2009;328:123-70.

4. Majii S, Thodima V, Sample R, Whitley D, Deng Y, Mao J, Chinchar VG. Transcriptome analysis of frog virus 3 , the type species of the genus Ranavirus, family Iridoviridae. Virol. 2009;391:293-303.

5. Teng Y, Hou Z, Gong J, Liu H, Xie X, Zhang L, Chen X, Qin QW. Wholegenome transcriptional profiles of a novel marine fish iridovirus, Singapore grouper iridovirus(SGIV) in virus-infected grouper spleen cell cultures and in orange-spotted grouper Epinephulus coioides. Virol. 2008; 377:39-48.

6. Williams T. Valérie Barbosa-Solomieu, Chinchar VG. A decade of advances in iridovirus research. Adv Virus Res. 2005;65:173-284.

7. Hyatt AD, Gould AR, Zupanovic Z, Cunningham AA, Hengstberger S, Whittington, RJ, Kattenbelt J, Coupar BEH. Comparative studies of piscine and amphibian iridoviruses. Arch Virol 2000;145:301-331.

8. Khalil MI, Sommer M, Arvin A, Hay J, Ruyechan WT. Cellular transcription factor YY1 mediates the varicella-zoster virus (VZV) IE62 transcriptional activation. Virol. 2014:449:244-53.

9. Huang PH, Huang TY, Cai PS, Chang LK, Mcfadden G. Role of Litopenaeus Vannamei Yin yang 1 in the regulation of the white spot syndrome virus immediate early gene IE1. J Virol. 2017;91:e02314-6.

10. Zi $Y$, Xiaomin $X$, Fang $L$, Feng $Y$. Characterization of the promoter of white spot syndrome virus immediate-early gene, wsv249. Virus Res. 2018;252:76-81.

11. Xia LQ, Liang HY, Huang YH, Ou-Yang ZL, Qin QW. Identification and characterization of Singapore grouper iridovirus(SGIV) ORF162L, an immediate-early gene involved in cell growth control and viral replication. Virus Res. 2010;147:30-9.

12. Beckman W, Tham TN, Aubertin AM, Willis DB. Structure and regulation of the immediate-early frog virus 3 gene that encodes ICR489. J Virol. 1988;62:1271-7.

13. Pallister J, Goldie S, Coupar B, Hyatt A. Promoter activity in the $5^{\prime}$ flanking regions of the Bohle iridovirus ICP 18, ICP 46 and major capsid protein genes. Arch Virol. 2005;150:1911-9.

14. Eaton HE, Metcalf J, Penny E, Tcherepanov V, Upton C, Brunetti CR. Comparative genomic analysis of the family Iridoviridae: re-annotating and defining the core set of iridovirus genes. Virol J. 2007;4:11.

15. Huang X, Huang Y, Gong J, Yan Y, Qin Q. W. (2008). Identification and characterization of a putative lipopolysaccharide-induced tnf-a factor (LITAF) homolog from Singapore grouper iridovirus. Biochem Biophys Res Commun. 2008;373:140-5.

16. Qin QW, Wu TH, Jia TL, Hegde A, Zhang RQ. Development and characterization of a new tropical marine fish cell line from grouper, Epinephelus coioides susceptible to iridovirus and nodavirus. J Virol Methods. 2006;131:58-64

17. Huang $X H$, Huang $Y H$, Ouyang $Z L, X u L$, Yan $Y$, Cui HC, Qin QW Singapore grouper iridovirus, a large DNA virus, induces nonapoptotic cell death by a cell type dependent fashion and evokes ERK signaling. Apoptosis. 2011;16:831-45.

18. Xia LQ, Cao JH, Huang XH, Qin QW. Characterization of Singapore grouper iridovirus(SGIV) ORF086R, a putative homolog of ICP18 involved in cell growth control and virus replication. Arch Virol. 2009;154:1409-16.

19. Song WJ, Qin QW, Qiu J, Huang CH, Wang F, Hew CL. Functional genomics analysis of Singapore grouper iridovirus: complete sequence determination and proteomic analysis. J Virol. 2004;78:12576-90.

20. Mcbryant SJ, Kassavetis GA, Gottesfeld JM. Repression of vertebrate RNA polymerase III transcription by DNA binding proteins located upstream from the transcription start site. J Mol Biol. 1995;250:315-26.

21. Escudé C, Giovannangeli C, Sun JS, Lloy DH, Che JK, Gryaznov SM Stable triple helices formed by oligonucleotide $\mathrm{N3}^{\prime} \rightarrow \mathrm{P5}^{\prime}$ phosphoramidates inhibit transcription elongation. P Natl Acad Sci USA. 1996:93:4365-9.

22. Dizman YA, Demirbag Z, Ince IA, Nalcacioglu R. Transcriptomic analysis of Chilo iridescent virus immediate early promoter. Virus Res. 2012;167: $353-7$.

23. Nalcacioglu R, Marks H, Vlak JM, Demirbag Z, van Oers MM. Promoter analysis of the Chilo iridescent virus DNA polymerase and major capsid protein genes. Virol. 2003;317:321-9.

24. Chinchar VG, Yu KH, Jancovich JK, Jancovich JK. The molecular biology of frog virus 3 and other iridoviruses infecting cold-blooded vertebrates. Viruses. 2011;3:1959-85.

25. Burke TW, Kadonaga JT. Drosophila TFIID binds to a conserved downstream basal promoter element that is present in many TATA-boxdeficient promoters. Genes Dev. 1996;10:711-24.

26. Kadonaga JT. The DPE, a core promoter element for transcription by RNA polymerase II. Exp Mol Med. 2002;34:259-64.

27. Kutach AK, Kadonaga JT. The downstream promoter element DPE appears to be as widely used as the TATA box in drosophila core promoters. Mol Cell Biol. 2000;20:4754-64.

28. Rhode SL. Trans-activation of parvovirus P38 promoter by the $76 \mathrm{~K}$ noncapsid protein. J Virol. 1985;55:886-9.

29. Opitz R, Braunbeck T, Bogi C, Pickford DB, Nentwig G, Oehlmann J. A cis downstream element participates in regulation of in vitro transcription initiation from the P38 promoter of minute virus of mice. J Virol. 1990;64:354-60.

30. Woerner AM, Weir JP. Characterization of the initiator and downstream promoter elements of herpes simplex virus 1 late genes. Virol. 1998;249: 219-30.

31. Suzuki MG, Kang WK, Maeda S. An element downstream of the transcription start site is required for activation of Bombyx mori nucleopolyhedrovirus bro-c promoter. Arch Virol. 2001;146:495-506.

32. Song W, Lin Q, Joshi SB, Lim TK, Hew CL. Proteomic studies of the Singapore grouper iridovirus. Mol Cell Proteomics. 2006;5:256-64.

33. Zhang HL, Zhou S, Xia LQ, Huang XH, Huang YH, Cao JH, Qin QW. Characterization of the VP39 envelope protein from Singapore grouper iridovirus. Can J Microbiol. 2015;61:924-37.

34. Li W, Zhang X, Weng S, Zhao G, He J, Dong C. Virion-associated viral proteins of a Chinese giant salamander (Andrias davidianus) iridovirus (genus Ranavirus) and functional study of the major capsid protein (MCP). Vet Microbiol. 2014;172:129-39.

35. Ozsahin E, van Oers MM, Nalcacioglu R, Demirbag Z. Protein-protein interactions among the structural proteins of chilo iridescent virus. J Gen Virol. 2018;99:851-9.

36. Ince IA, Boeren SA, van Oers MM, Vervoort JJ, Vlak JM. Proteomic analysis of Chilo iridescent virus. Virol. 2010;405:253-8

37. Shuang $F$, Luo $Y$, Xiong XP, Weng $S$, Li Y, He J. Virions proteins of an RSIV-type megalocytivirus from spotted knifejaw Oplegnathus punctatus (SKIV-ZJ07). Virol. 2013:437:89-99.

38. Wong CK, Young VL, Kleffmann T, Ward VK. Genomic and proteomic analysis of invertebrate iridovirus type 9. J Virol. 2011;85:7900-11.

39. Sinani D, Cordes E, Workman A, Thunuguntia P, Jones C. Stress-induced cellular transcription factors expressed in trigeminal ganglionic neurons stimulate the herpes simplex virus 1 ICP0 promoter. J Virol. 2013;87: 13042-7.

40. Chang PJ, Wang SS, Chen LY, Hung $C H$, Huang HY, Shih YJ, Yen JB, Liou JY, Chen LW. ORF50-dependent and ORF50-independent activation of the ORF45 gene of Kaposi's sarcoma-associated herpesvirus. Virol. 2013;442:38-50

41. Huang $X D$, Zhao $L$, Zhang $H Q$, Xu XP, Jia XT, Chen $Y H$, Wang $P H$, Weng $S P$, Yu XQ, Yin ZX, He JG. Shrimp NF-kappaB binds to the immediate-early gene IE1 promoter of white spot syndrome virus and upregulates its activity. Virol. 2010;406:176-80.

42. Dai $Y$, Zhang R, Lin YX. 2006. The probability distribution of distance TSS-TLS is organism characteristic and can be used for promoter prediction [C]// advances in applied artificial intelligence, 19th international conference on industrial, engineering and other applications of applied intelligent systems, IEA/AIE 2006, Annecy, France, June 27-30, Proceedings. DBLP.

\section{Publisher's Note}

Springer Nature remains neutral with regard to jurisdictional claims in published maps and institutional affiliations. 